\title{
Effect of Electrodeposition Time on Absorptance, Roughness and Thermal Stability of Black Chromium Absorbing Surfaces
}

\author{
João Victor Furtado Frazão de Medeiros ${ }^{a *}$ (), Aline da Silva Oliveira ${ }^{b}$ (1), \\ Gabriela Oliveira Galvão ${ }^{b}$ (1), Ithyara Dheylle Machado de Medeiros ${ }^{c}$ (1), Kelly Cristiane Gomes ${ }^{b, d}$ (1) \\ ${ }^{a}$ Universidade Federal de Pernambuco (UFPE), Programa de Pós Graduação em Tecnologias \\ Energéticas e Nucleares, Recife, PE, Brasil. \\ ${ }^{b}$ Universidade Federal de Paraiba (UFPB), Programa de Pós Graduação em Engenharia Mecânica, \\ João Pessoa, PB, Brasil. \\ ${ }^{c}$ Universidade Federal da Paraiba (UFPB), Departamento de Engenharia Mecânica, João Pessoa, PB, \\ Brasil. \\ ${ }^{d}$ Universidade Federal de Paraiba (UFPB), Departamento de Engenharia de Energias Renováveis, \\ João Pessoa, PB, Brasil.
}

Received: September 22, 2021; Revised: January 11, 2022; Accepted: February 01, 2022

\begin{abstract}
Solar thermal energy is one of the ways of using solar radiation that can be applied to meet the energy needs for heating. To achieve efficient photothermal conversion, selective surfaces are applied to solar collectors to absorb more radiation and minimize heat loss. The present work produced absorber surfaces from black chromium electrodeposition on stainless steel substrate, the main parameter evaluated was the deposition time and its effect on optical and morphological properties. In this sense, the techniques of characterization UV-Vis-NIR Spectroscopy, Infrared Spectroscopy, X-Ray Diffraction, Optical Profilometry and Thermogravimetric analysis were used. It was observed a great influence of the electrodeposition time in the absorptance of the films, where films with deposition times of 2 to 10 minutes obtained absorptances greater than $92 \%$. The metallic $\mathrm{Cr}$ phase was identified in the films, and it is estimated that chromium oxides may have been formed in the amorphous form. With increasing time, the roughness oscillated due to the constant nucleation of chromium throughout the process. Furthermore, a $5 \%$ mass loss indicates good thermal stability of the film up to $400{ }^{\circ} \mathrm{C}$.
\end{abstract}

Keywords: Solar thermal energy, Absorber films, Black Chromium, Electrodeposition.

\section{Introduction}

Despite the reductions in $\mathrm{CO}_{2}$ emissions presented in 2020 , given the pandemic scenario and the registered decrease in fossil fuel demand, global emissions reached the highest average annual concentration in the atmosphere, corresponding to 412.5 parts per million ${ }^{1}$. The increase of $\mathrm{CO}_{2}$ levels in the atmosphere leads to an increment in Earth's temperature and, consequently, to an ecological imbalance, thus arousing enthusiasm for clean and renewable energy sources ${ }^{2}$.

Among the various renewable energy sources, solar energy is an abundant, freely available energy source with high potential for small and large scale applications. Solar energy can be categorized into photovoltaic and solar thermal $^{3}$. The direct conversion of solar energy into heat (solar thermal) can be achieved through the use of solar collectors. A large fraction of energy resources is nowadays used for heating and this energy demand can be supplied by solar thermal collectors ${ }^{4}$.

An efficient way to achieve photothermal conversion is through the use of selective absorber surfaces. These

*e-mail: joao.furtado@ufpe.br surfaces should have high absorptance in the spectral range of solar radiation and low emittance in the infrared range, to minimize the loss of thermal radiation and allow greater energy transfer to a working fluid 5 .

The optical efficiency of the absorber coating is given not only by the materials used, the number of layers and the morphology control, but also by the technique employed to produce the film. Several techniques are commonly used in the production of absorber coatings, such as painting, electrodeposition, chemical vapor deposition (CVD), sputtering, sol-gel and chemical oxidation ${ }^{6}$. However, due to the simplicity of application, low cost and high efficiency in photothermal conversion ${ }^{7}$, the present study was based on the production of absorber surfaces by electrodeposition.

Electrodeposition is one of the most widely used techniques in the manufacture of solar absorbers. In order to achieve the desired mechanical and optical properties for application in solar collectors it is essential to control the electrochemical parameters involved and understand their influence on the optical properties of the material ${ }^{8}$. One of the factors that influence the results obtained from the electrodeposition is the time. Several authors choose to establish fixed conditions (distance between electrodes, voltage, among others) and 
evaluate the surfaces with various times ${ }^{7-11}$, aiming to obtain efficient selective surfaces.

In this paper, we evaluate the influence of the electrodeposition time on the optical and morphological properties of selective coatings on stainless steel based on black chromium, increasing in the analysis electrodeposition times higher than those discussed in the literature and based on some fixed parameters established.

\section{Experimental Techniques}

\subsection{Samples preparation}

An inert $\mathrm{Pb}$-Sb anode (95-5\%) was used to obtain the films by the electrodeposition technique, while the cathode used was the AISI 304 stainless steel substrate with dimensions of $20 \mathrm{~mm}$ x $30 \mathrm{~mm}$ and thickness of $3 \mathrm{~mm}$. The electrolyte solution used for fabrication of the selective surfaces is black chromium and was prepared following the work methodology of Daryabegy and Mahmoodpoor ${ }^{12}$, whose composition is $274 \mathrm{~g} / \mathrm{l}$ of chromium trioxide $\left(\mathrm{CrO}_{3}\right)$ and $0.854 \mathrm{~g} / 1$ of hexafluorosilicic acid $\left(\mathrm{H}_{2} \mathrm{SiF}_{6}\right)$.

Before the electrodeposition process of black chrome, the substrates were cleaned to remove any impurities. First, the cleaning consisted of immersing the plates in isopropyl alcohol for 10 minutes in an ultrasonic bath, then they were washed with distilled water, and once dried, the substrates were then prepared for the electrodeposition process.

To perform the electrodeposition, an Agilent model E3631A power supply was used as a current source. A voltage of $5 \mathrm{~V}$ was established based on results obtained in the literature ${ }^{8,11}$. In addition, the electrodes were spaced $30 \mathrm{~mm}$ apart, temperature was set at $30^{\circ} \mathrm{C}$, and the electrodeposition time was varied in 9 conditions $(0.5,1,2,5,10,20,40,60$, and 120 minutes).

Table 1 presents the parameters adopted in the present research.

The analysis was performed in triplicate for each electrodeposition time, totaling 27 samples, to ensure a level of reproducibility and confidence in the absorptance results of the films.

\subsection{Samples characterization}

The total hemispherical absorptance $(\alpha)$ of the solid is given by the mean integrated with respect to the wavelength direction, conformity Equation $1^{13}$.

Table 1. Parameters adopted.

\begin{tabular}{|c|c|c|c|}
\hline Sample & Distance & Voltage & $\begin{array}{c}\text { Time } \\
\text { (minutes) }\end{array}$ \\
\hline 1 & & & 0.5 \\
\hline 2 & & & 1 \\
\hline 3 & & & 2 \\
\hline 4 & & & 5 \\
\hline 5 & $30 \mathrm{~mm}$ & $5 \mathrm{~V}$ & 10 \\
\hline 6 & & & 20 \\
\hline 7 & & & 40 \\
\hline 8 & & & 60 \\
\hline 9 & & & 120 \\
\hline
\end{tabular}

$$
\alpha=\frac{\int_{220}^{1400} \alpha_{\lambda} I_{\text {solar }, \lambda} d \lambda}{\int_{220}^{1400} I_{\text {solar }, \lambda} d \lambda}
$$

Being $I_{\text {solar } \lambda}$ the spectral distribution of solar irradiance, $\alpha$ is the spectral solar absorptance and $\lambda$ is each wavelength of the analyzed spectrum.

As it is an opaque material, it was possible to evaluate the spectral solar absorptance $\left(\alpha_{\lambda}\right)$ of the solid from the spectral solar reflectance $\left(\rho_{\lambda}\right)$, both are related as shown in Equation 2.

$\alpha_{\lambda}=1-\rho_{\lambda}$

In this manner the total hemispherical absorptance $(\alpha)$, also known as global absorptance, can be obtained through Equation 3 from reflectance measurements obtained by the technique of ultraviolet spectroscopy using a Shimadzu Spectrophotometer model UV-2600 with integration sphere operating in the range of 220 to $1400 \mathrm{~nm}$ in reflectance mode.

$\alpha=\frac{\int_{220}^{1400}\left(1-\rho_{\lambda}\right) I_{\text {solar }, \lambda} d \lambda}{\int_{220}^{1400} I_{\text {solar }, \lambda} d \lambda}$

To understand the composition structure of the films, Fourier Transform Infrared Spectroscopy was performed with a Spectrophotometer Shimadzu IR-Prestige 21 in Attenuated Total Reflectance (ATR) mode, in the range between 600 and $4000 \mathrm{~cm}^{-1}$ in transmittance mode.

In order to identify the microstructural composition in terms of crystallinity of the chromium compounds present in the film, X-Ray Diffraction was used in a Bruker D2-Phaser diffractometer, operating with copper $\mathrm{K} \alpha$ radiation, whose parameters were voltage and current of $30 \mathrm{mV}$ and $10 \mathrm{~mA}$, respectively, with $2 \theta$ scan between $20^{\circ}$ and $60^{\circ}$, with $0.02^{\circ}$ step, $1 \mathrm{~s}$ time and $1 \mathrm{~mm}$ gap.

Optical Profilometry was conducted to measure the average roughness $\left(R_{\mathrm{p}}\right)$, the average peak $\left(\mathrm{R}_{\mathrm{p}}\right)$ and valleys $\left(R_{\mathrm{v}}\right)$ of all samples analyzed. This analysis was performed using a Taylor Hobson non-contact CCI MP profilometer.

The samples were also submitted to Thermogravimetric analysis, using a Shimadzu TGA $60 \mathrm{H}$ thermal analyzer, in the temperature range up to $600{ }^{\circ} \mathrm{C}$, with heating rate of $5{ }^{\circ} \mathrm{C} / \mathrm{min}$ up to $100{ }^{\circ} \mathrm{C}$ and $10{ }^{\circ} \mathrm{C} / \mathrm{min}$ up to $600{ }^{\circ} \mathrm{C}$. In order to evaluate the thermal stability of the material and to estimate the most suitable working temperature range for the selective surfaces, a nitrogen atmosphere with a flow rate of $50 \mathrm{ml} / \mathrm{min}$ was used.

\section{Results and Discussion}

\subsection{UV-VIS-NIR spectroscopy}

Figure 1 and Table 2 show, the optical behavior, in terms of absorptance, of each film produced in this work.

It can be observed from Figure 1 that the 10-minute film showed throughout the spectrum evaluated a higher stability in absorptance levels, and among the others it was the one with the best performance $(94.65 \%)$ regarding the trapping 
of incident radiation, followed by the 5 and 2-minute films, respectively, (92.64\% and $92.44 \%$ ).

The shortest electrodeposition times, between 2 and 10 minutes, provided films with high levels of absorptance, as according to the literature ${ }^{7,8,14}$. In the present work, it was evidenced that the times of 30 seconds and 1 minute for the parameters of $30 \mathrm{~mm}$ distance and $5 \mathrm{~V}$ produced selective surfaces with lower levels of absorptance, a fact that may have had as its main cause is the non-nucleation of chromium throughout the substrate, thus decreasing the performance of the absorbing surfaces.

In Table 2 it is observed that the selective surfaces that had electrodeposition time longer than 20 minutes showed lower standard deviation and similar global absorptances. However, the non-viability of such films is observed since the absorptance levels are not significantly higher than those of shorter time, and the production costs rise as the electrodeposition time increases.

Despite presenting a high standard deviation, films 3, 4 and 5 showed high levels of global absorptance, the 10-minute film had the best performance for the conditions evaluated.

The graph shown in Figure 2 represents the global absorptance of all samples as a function of electrodeposition time.

When evaluating the behavior of the global absorptance of all samples (Figure 2), it is observed for short electrodeposition

Table 2. Global absorptances of the films.

\begin{tabular}{cccc}
\hline Sample & Time (min) & $\begin{array}{c}\text { Global } \\
\text { absorptance } \\
(\mathbf{\%})\end{array}$ & $\begin{array}{c}\text { Standard } \\
\text { deviation (\%) }\end{array}$ \\
\hline 1 & 0.5 & 87.87 & 2.73 \\
\hline 2 & 1 & 90.88 & 1.98 \\
\hline 3 & 2 & 92.44 & 1.32 \\
\hline 4 & 5 & 92.64 & 3.45 \\
\hline 5 & 10 & 94.65 & 2.85 \\
\hline 6 & 20 & 92.00 & 1.01 \\
\hline 7 & 40 & 90.89 & 0.21 \\
\hline 8 & 60 & 91.17 & 0.25 \\
\hline 9 & 120 & 91.07 & 0.31 \\
\hline
\end{tabular}

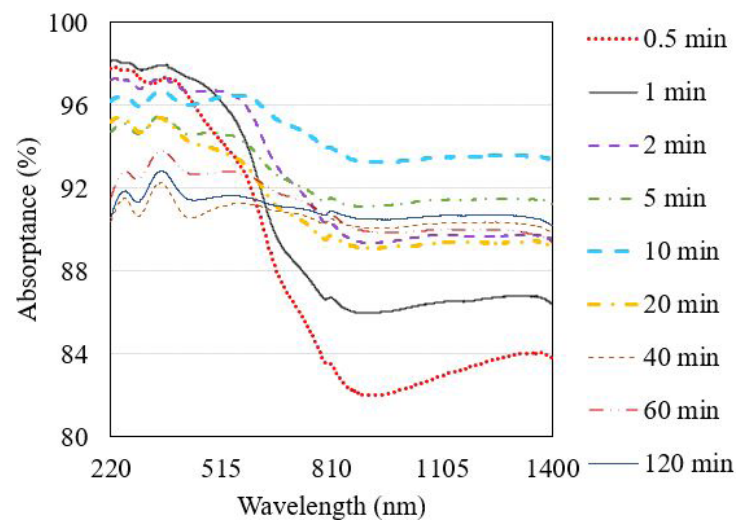

Figure 1. Absorptance spectroscopy in the UV-Vis-NIR range of the produced films. times (highlighted in red), a strong increase in the absorptance as a function of time. However, after 20 minutes, the global absorptance of the selective surfaces tend to stabilize between values of 90 to $92 \%$, with less dispersion (variability) (see Table 2).

\subsection{FTIR spectroscopy}

Figure 3 shows the Infrared spectroscopy (FTIR) in the mid-infrared in terms of transmittance.

Metal oxide generally reveal absorption bands below $1000 \mathrm{~cm}^{-1}$ due to inter-atomic vibrations ${ }^{15}$. The large bands are an indication of disordered structure, that is, of the nearly amorphous nature of the absorber surfaces. The absorption band at $950 \mathrm{~cm}^{-1}$ indicates the vibration of the antisymmetric $\mathrm{O}-\mathrm{Cr}-\mathrm{O}$ stret-ching ${ }^{16}$, while the vibrational band between 650 and $700 \mathrm{~cm}^{-1}$ corresponds to the elongation of the $\mathrm{Cr}-\mathrm{O}$ bond ${ }^{17}$. The identified vibrations correspond to the bonds resulting from the formation of chromium-based oxides. The band at $1600 \mathrm{~cm}^{-1}$ may be associated with -OH stretching of modes of the water molecule, and between $3000 \mathrm{~cm}^{-1}$ and $3600 \mathrm{~cm}^{-1}$ with the bending modes of this same molecule ${ }^{18}$.

\subsection{X-Ray diffraction}

Figure 4 shows the X-Ray diffraction of the films analyzed.

As seen in Figure 4, only characteristic peaks of austenite phase (Fe- $\gamma$ ) of the stainless steel substrate (ICDD 00-033-0397)

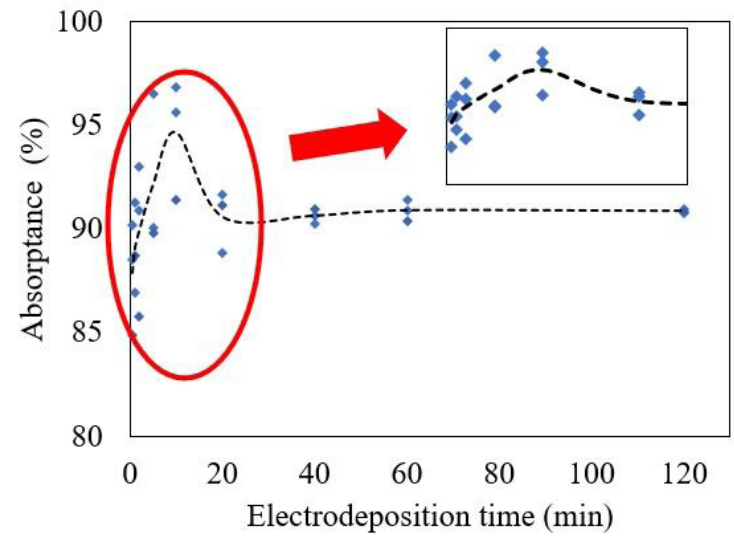

Figure 2. Global absorptance of all samples. Short time samples highlighted.

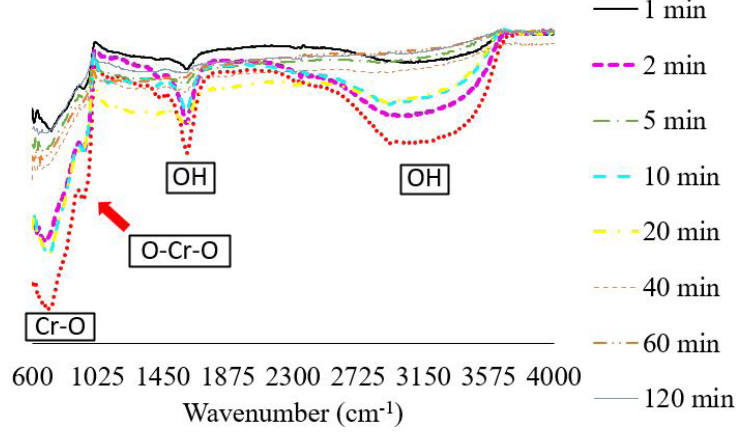

Figure 3. FTIR Spectroscopy. 
are evidenced in the samples deposited in the shortest times, from 30 seconds to 2 minutes. Due to the thin film thickness, the radiation interacts with the substrate and not with the deposited film. From the deposition time of 5 minutes, the film thickness is sufficient to identify the metallic chromium phase in the film, at the peak around $45.00^{\circ}$ (ICDD 00-006-0694), results also observed in Nunes ${ }^{10}$. The Cr peak intensifies as the film thickness increases, which is a consequence of the increased electrodeposition time. In film 9 (120 minutes), the austenite phase disappears completely, as incident radiation beam only interacts with the film volume.

It is possible that chromium oxide phases are present in the produced films in an amorphous form, as discussed in Figure 3, not being identified in the diffractograms.

\subsection{Optical profilometry}

The optical profilometry was performed in order to evaluate the characteristics of the films regarding roughness. Through the analysis we obtained the average roughness of the films $\left(R_{a}\right)$, as well as the average peak $\left(R_{p}\right)$ and the average of the identified valleys $\left(R_{v}\right)$, presented in Table 3 along with the respective global absorptances.

The roughness is a fundamental characteristic in defining the radiation absorption capacity in the visible and near infrared region. Thus, it can be seen in Table 3 that the increase in roughness leads to an increase in absorptance until the time of $10 \mathrm{~min}^{11}$. For longer electrodeposition time, increasing $\mathrm{R}_{\mathrm{p}}, \mathrm{R}_{\mathrm{v}}$ and $\mathrm{R}_{\mathrm{a}}$ parameters does not increase light trapping.

(1) $\mathrm{Fe}(\gamma)$ (2) $\mathrm{Cr}$

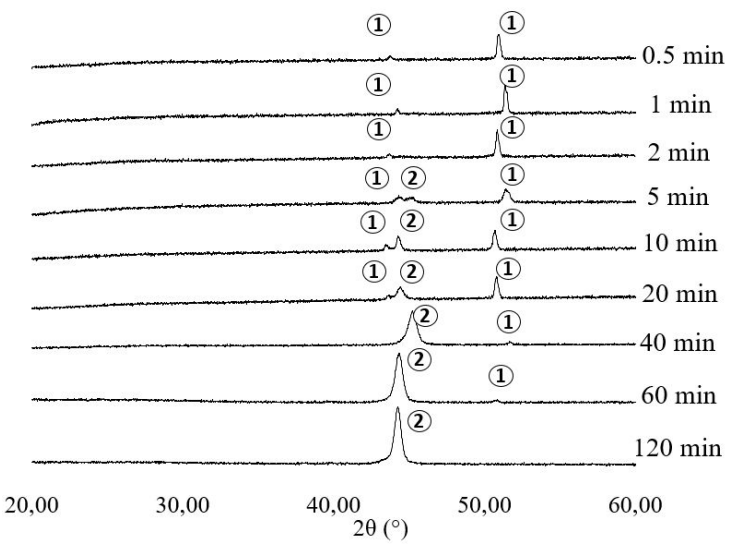

Figure 4. Diffractograms of the produced films.

Table 3. Roughness parameters.

\begin{tabular}{cccccc}
\hline Sample & $\begin{array}{c}\text { Time } \\
(\mathbf{m i n})\end{array}$ & $\begin{array}{c}\mathbf{R}_{\mathbf{p}} \\
(\boldsymbol{\mu m})\end{array}$ & $\begin{array}{c}\mathbf{R}_{\mathbf{v}} \\
(\boldsymbol{\mu \mathbf { m }})\end{array}$ & $\begin{array}{c}\mathbf{R}_{\mathrm{a}} \\
(\boldsymbol{\mu \mathbf { m } )}\end{array}$ & $\begin{array}{c}\text { Absorptance } \\
(\mathbf{\%})\end{array}$ \\
\hline 1 & 0.5 & 0.162 & 0.123 & 0.049 & 87.87 \\
\hline 2 & 1 & 0.101 & 0.129 & 0.037 & 90.88 \\
\hline 3 & 2 & 0.136 & 0.167 & 0.026 & 92.44 \\
\hline 4 & 5 & 0.818 & 0.543 & 0.196 & 92.64 \\
\hline 5 & 10 & 2.125 & 1.367 & 0.337 & 94.65 \\
\hline 6 & 20 & 0.297 & 0.255 & 0.073 & 92.00 \\
\hline 7 & 40 & 6.815 & 5.786 & 0.989 & 90.89 \\
\hline 8 & 60 & 7.169 & 7.058 & 1.111 & 91.17 \\
\hline 9 & 120 & 11.444 & 9.902 & 1.405 & 91.07 \\
\hline
\end{tabular}

Besides the best result in terms of absorptance was achieved by film 5 , it presented high values of $R_{p}$ and $R_{v}$, which can be identified in red in Figure 5, as peaks and valleys. Even with such a characteristic, it is observed in Figure 5 a greater uniformity of the film, compared to the worst film (Figure 6) that presents an irregular surface, thus difficulting the trapping of incident radiation. Moreover, film 5 presented $\mathrm{R}_{\mathrm{a}}$ within the range of interest $(0.25$ to $2.5 \mu \mathrm{m})$ and low average difference between peaks and valleys, thus obtaining high performance regarding radiation trapping.

\subsection{Thermogravimetry}

In order to evaluate the thermal stability of the produced chromium-based films, a sample was submitted to thermogravimetric analysis.

The weight loss is presented in Figure 7.

Figure 7 shows that the chrome-based film presents a good thermal stability in the temperature range of interest (up to $400{ }^{\circ} \mathrm{C}$ ), since there is a weight loss of approximately

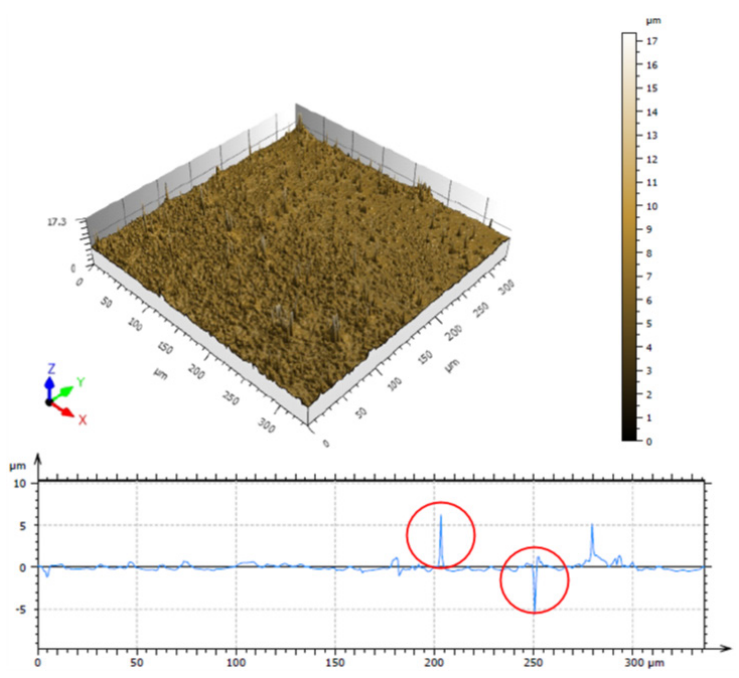

Figure 5. Best absorptance result, Film 5.

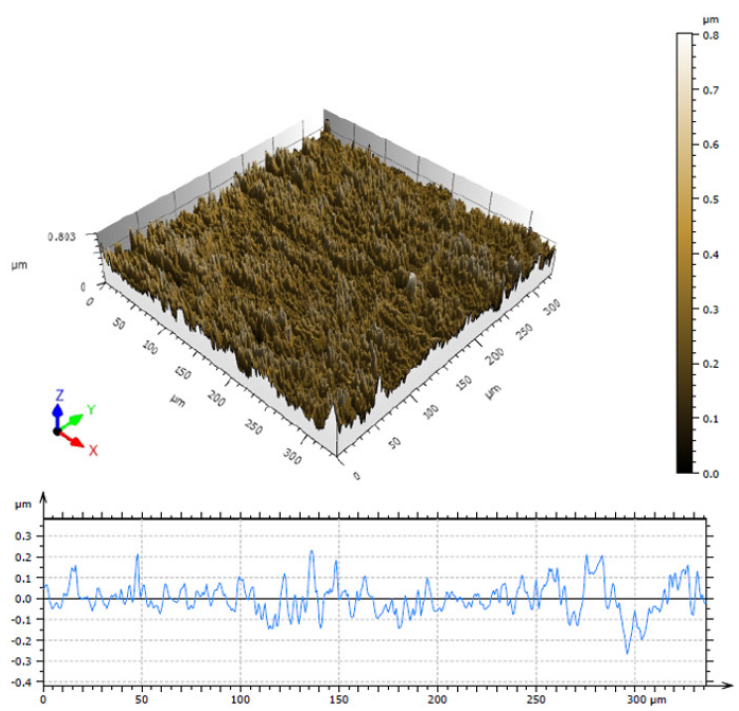

Figure 6. Worst absorptance result, Film 1. 


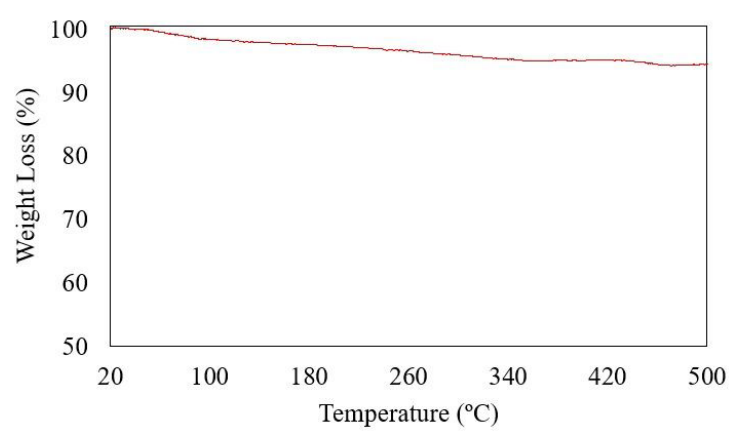

Figure 7. Thermogravimetric Analysis.

$5 \%$. The existing weight loss can be mitigated through the use of another film or other components with thermal and mechanical properties that provide greater thermal stability for the solar collector ${ }^{6}$.

\section{Conclusion}

The vast majority of absorbent coatings produced had global absorptance greater than $90 \%$, with a maximum reached of $94.6 \%$, thus being able to be applied as selective surfaces in solar collectors.

By varying the time as a function of the deposition parameters adopted $(30 \mathrm{~mm}$ distance and $5 \mathrm{~V})$ the 10 -minute time obtained the best results. In addition, it was observed that for the samples with short electrodeposition time, the increase in time tends to lead to a better production of efficient absorber coatings. However, after 20 minutes the standard deviation between the absorptance of the coatings produced tends to be minimal.

A crystalline phase of metallic $\mathrm{Cr}$ was identified in films of greater thickness obtained in longer deposition times, however there are indications that chromium oxides may have been formed in the amorphous form.

The roughness determined in the profilometry varied in an oscillatory way as a function of the increase in the deposition time. However, it was possible to observe that the sample with the highest absorptance presented greater uniformity and $\mathrm{R}_{\mathrm{a}}$ value within the range of interest.

Through the thermal characterization it was observed a weight loss up to $400{ }^{\circ} \mathrm{C}$ of approximately $5 \%$, which can be improved by apply another film to compose the selective surface in order to optimize the thermal properties of the solar absorber, ensuring greater thermal stability and less optical loss, as is the case of Cermet $^{19}$.

\section{Acknowledgments}

The authors thank the National Council for Scientific and Technological Development (CNPq) for the financial support (No 472793/2013-6 and 313531/2019-6). As well as the Human Resources Training Program of the Brazilian National Agency for Petroleum, Natural Gas and Biofuels (PRH-ANP), the Coordination for the Improvement of
Higher Education Personnel (CAPES) and the CNPq for the support to the fellows in the scope of their respective post-graduation programs. In addition, to the members of the Federal University of Paraíba (UFPB) laboratories for their technical support.

\section{References}

1. International Energy Agency. Global energy review 2021: $\mathrm{CO}_{2}$ emissions [Internet]. Paris: IEA; 2021 [cited 2021 Sept 22]. Available from: https://www.iea.org/reports/global-energyreview-2021/co2-emissions

2. Banday UJ, Aneja R. Renewable and non-renewable energy consumption, economic growth and carbon emission in BRICS: evidence from bootstrap panel causality. Int J Energy Sect Manage. 2020;14(1):248-60.

3. Malinowski M, Leon JI, Abu-Rub H. Solar photovoltaic and thermal energy systems: current technology and future trends. Proc IEEE. 2017;105(11):2132-46.

4. De Maio D, D'alessandro C, Caldarelli A, De Luca D, Di Gennaro E, Russo R, et al. A selective solar absorber for unconcentrated solar thermal panels. Energies. 2021;14(4):900.

5. Zhao S. Spectrally selective solar absorbing coatings prepared by dc magnetron sputtering [thesis]. Uppsala: Uppsala University; 2007.

6. Kennedy CE. Review of mid to high-temperature solar selective absorber materials. New York: NREL; 2002.

7. Quintana J, Sebastian PJ. The influence of various substrate treatments on morphology and selective absorber characteristics of electrochemical black chrome. Solar Cells. 1994;33(4):465-74.

8. Medeiros IDM, Gomes KC, Gonçalves RPN, Galvão GO. Selective solar surface solar based on black chromium: influence of electrodeposition parameters in the absorption of surfaces. Mater Res. 2019;22(2):e20180625.

9. Window B, Ritchie IT, Cathro K. Selective electroplated chromium blacks. Appl Opt. 1978;17(16):2637-44.

10. Nunes RAX, Costa VC, Sade W, Araújo FR, Silva GM. Selective surfaces of black chromium for use in solar absorbers. Mater Res. 2017;21(1).

11. Medeiros IDM, Gonçalves RPN, Menezes VL, Galvão GO, Gomes KC. Evaluation of potential residual silica as antireflective layer for selective solar surface of black chromium. Mater Res. 2019;22(3):e20180750.

12. Daryabegy M, Mahmoodpoor AR. Method of manufacturing absorbing layers on copper for solar applications. IESCO J Sci Technol. 2006;2(1):35-9.

13. Bergman TL, Incropera FP, DeWitt DP, Lavine AS. Fundamentals of heat and mass transfer. Hoboken: John Wiley \& Sons. 2011.

14. Jafari S, Rozati SM. Characterization of black chrome films prepared by electroplating technique. In: World Renewable Energy Congress; 2011; Linköping, Sweden. Proceedings. Linköping: Linköping University; 2011. p. 3999-4005. (no. 57).

15. Salehi M, Ghasemi F. Preparation of chromium (III) oxide sub-micron powders by solid state method without fuel. J Appl Chem. 2015;9(32):97-100.

16. Hou X, Choy KL, Brun N, Serín V. Nanocomposite coatings co-deposited with nanoparticles using aerosol-assisted chemical vapour deposition. J Nanomater. 2013;2013:1.

17. Sone BT, Manikandan E, Gurib-Fakim A, Maaza M. Single-phase $\alpha-\mathrm{Cr} 2 \mathrm{O} 3$ nanoparticles' green synthesis using Callistemon viminalis' red flower extract. Green Chem Lett Rev. 2016;9(2):85-90.

18. Liu Q, Ning L, Zheng S, Tao M, Shi Y, He Y. Adsorption of carbon dioxide by MIL-101 $(\mathrm{Cr})$ : regeneration conditions and influence of flue gas contaminants. Sci Rep. 2013;3(1):1-6.

19. Silva JF No, Torres SM, Gomes KC, Lima MRF Fo, Gomes RM. Chromium silica co-sputtered graded Cermet for solar thermal collectors. Sol Energy. 2019;193:212-9. 